\title{
CAPS1 Deficiency Perturbs Dense-Core Vesicle Trafficking and Golgi Structure and Reduces Presynaptic Release Probability in the Mouse Brain
}

\author{
Tetsushi Sadakata, ${ }^{1,3}$ Wataru Kakegawa, ${ }^{4}$ Yo Shinoda, ${ }^{3,5}$ Mayu Hosono, ${ }^{1}$ Ritsuko Katoh-Semba, ${ }^{5}$ Yukiko Sekine, ${ }^{5}$ \\ Yumi Sato, ${ }^{6,7}$ Mika Tanaka, ${ }^{8}$ Takuji Iwasato, ${ }^{9}$ Shigeyoshi Itohara, ${ }^{8}$ Kenichiro Furuyama, ${ }^{10}$ Yoshiya Kawaguchi, ${ }^{10}$ \\ Yasuki Ishizaki, ${ }^{2}$ Michisuke Yuzaki, ${ }^{4}$ and Teiichi Furuichi ${ }^{3,5}$ \\ ${ }^{1}$ Advanced Scientific Research Leaders Development Unit and ${ }^{2}$ Department of Molecular and Cellular Neurobiology, Graduate School of Medicine, Gunma \\ University, Maebashi, Gunma 371-8511, Japan, ${ }^{3}$ Japan Science and Technology Agency/Core Research for Evolutional Science and Technology, Kawaguchi, \\ Saitama 332-0012, Japan, ${ }^{4}$ Department of Physiology, School of Medicine, Keio University, Tokyo 160-8582, Japan, ${ }^{5}$ Department of Applied Biological \\ Science, Tokyo University of Science, Noda, Chiba 278-8510, Japan, ${ }^{6}$ Graduate School of Medical Science, Department of Molecular Virology and Oncology, \\ Cancer Research Institute, Kanazawa University, Kanazawa, Ishikawa 920-1192, Japan, ${ }^{7}$ Department of Biochemistry, Osaka Medical Center for Cancer and \\ Cardiovascular Diseases, Osaka 537-8511, Japan, ${ }^{8}$ Laboratory for Behavioral Genetics, Funding Program for World-Leading Innovative R\&D on Science and \\ Technology, RIKEN Brain Science Institute, Wako, Saitama 351-0198, Japan, ${ }^{9}$ Department of Developmental Genetics, National Institute of Genetics, \\ Mishima, Shizuoka 411-8540, Japan, and ${ }^{10}$ Department of Clinical Application, Center for iPS Cell Research and Application, Kyoto University, Kyoto \\ 606-8507, Japan
}

$\mathrm{Ca}^{2+}$-dependent activator protein for secretion 1 (CAPS1) plays a regulatory role in the dense-core vesicle (DCV) exocytosis pathway, but its functions at the cellular and synaptic levels in the brain are essentially unknown because of neonatal death soon after birth in Caps 1 knock-out mice. To clarify the functions of the protein in the brain, we generated two conditional knock-out (cKO) mouse lines: 1) one lacking Caps1 in the forebrain; and 2) the other lacking Caps1 in the cerebellum. Both cKO mouse lines were born normally and grew to adulthood, although they showed subcellular and synaptic abnormalities. Forebrain-specific Caps1 cKO mice showed reduced immunoreactivity for the DCV marker secretogranin II (SgII) and the trans-Golgi network (TGN) marker syntaxin 6, a reduced number of presynaptic DCVs, and dilated trans-Golgi cisternae in the CA3 region. Cerebellum-specific Caps $1 \mathrm{cKO}$ mice had decreased immunoreactivity for SgII and brain-derived neurotrophic factor (BDNF) along the climbing fibers. At climbing fiber-Purkinje cell synapses, the number of DCVs was markedly lower and the number of synaptic vesicles was also reduced. Correspondingly, the mean amplitude of EPSCs was decreased, whereas paired-pulse depression was significantly increased. Our results suggest that loss of CAPS1 disrupts the TGN-DCV pathway, which possibly impairs synaptic transmission by reducing the presynaptic release probability.

\section{Introduction}

The $\mathrm{Ca}^{2+}$-dependent activator protein for secretion (CAPS) family is involved in dense-core vesicle (DCV) release (Walent

Received June 28, 2013; revised Sept. 6, 2013; accepted Sept. 26, 2013.

Author contributions: T.S. and T.F. designed research; T.S., W.K., Y. Shinoda, M.H., R.K.-S., Y. Sekine, and Y. Sato performed research; T.S., W.K., Y. Shinoda, M.H., R.K.-S., Y. Sato, M.T., T.I., S.I., K.F., Y.K., Y.I., and M.Y. analyzed data; T.S., W.K., and T.F. wrote the paper.

This study was supported by Grants-in-Aid for Scientific Research from the Japan Foundation for Neuroscience and Mental Health, the Uehara Memorial Foundation, the Takeda Science Foundation, the Nakajima Foundation, the Yamada Science Foundation, the Mother and Child Health Foundation, the NOVARTIS Foundation for the Promotion of Science, the Inamori Foundation, Scientific Research on Innovative Areas "Foundation of Synapse and Neurocircuit Pathology," the CREST and FIRST program of the Japan Science and Technology Agency, Japanese Ministry of Education, Culture, Sports, Science, and Technology (MEXT) Grant 25110707, the Japan Society for the Promotion of Science Grant 25430061, the Institute of Physical and Chemical Research (RIKEN Brain Science Institute), and the Program to Disseminate Tenure Tracking System of MEXT granted to Gunma University.

The authors declare no competing financial interests.

Correspondence should be addressed to either of the following: Teiichi Furuichi, Department of Applied Biological Science, Tokyo University of Science, Noda, Chiba 278-8510, Japan, E-mail: tfuruichi@rs.tus.ac.jp; or Tetsushi Sadakata, Gunma University, Maebashi, Gunma 371-8511, Japan, E-mail: sadakata-1024@umin.ac.jp.

DOI:10.1523/JNEUROSCI.2777-13.2013

Copyright $\odot 2013$ the authors $\quad 0270-6474 / 13 / 3317326-09 \$ 15.00 / 0$ et al., 1992; Ann et al., 1997; Berwin et al., 1998; Tandon et al., 1998; Renden et al., 2001; Grishanin et al., 2004; Liu et al., 2008; Sadakata et al., 2010). In mammals, there are two family members, CAPS1 (Berwin et al., 1998) and CAPS2 (Speidel et al., 2003; Sadakata et al., 2004, 2007a,b). Previous studies have shown that CAPS1 deficiency affects the secretion of catecholamines [e.g., norepinephrine (Berwin et al., 1998; Tandon et al., 1998)], neuropeptides [e.g., neuropeptide Y (Fujita et al., 2007)], and peptide hormones [e.g., insulin (Speidel et al., 2008)].

Our previous studies showed that CAPS1 interacts with the Golgi membrane and the class II ADP ribosylation factor (ARF) small GTPases (ARF4 and ARF5) and that CAPS1 knockdown (KD) and ARF-binding mutations result in abnormal morphology of the trans-Golgi network (TGN) and a decrease in the number of DCVs, suggesting that CAPS1 has a functional role in the trafficking pathway between TGN and DCVs (Sadakata et al., 2010). Similar experiments on CAPS2 also suggest a role for the CAPS family in the TGN-DCV pathway (Sadakata et al., 2012). However, the cellular and biochemical functions of CAPS1 in the 


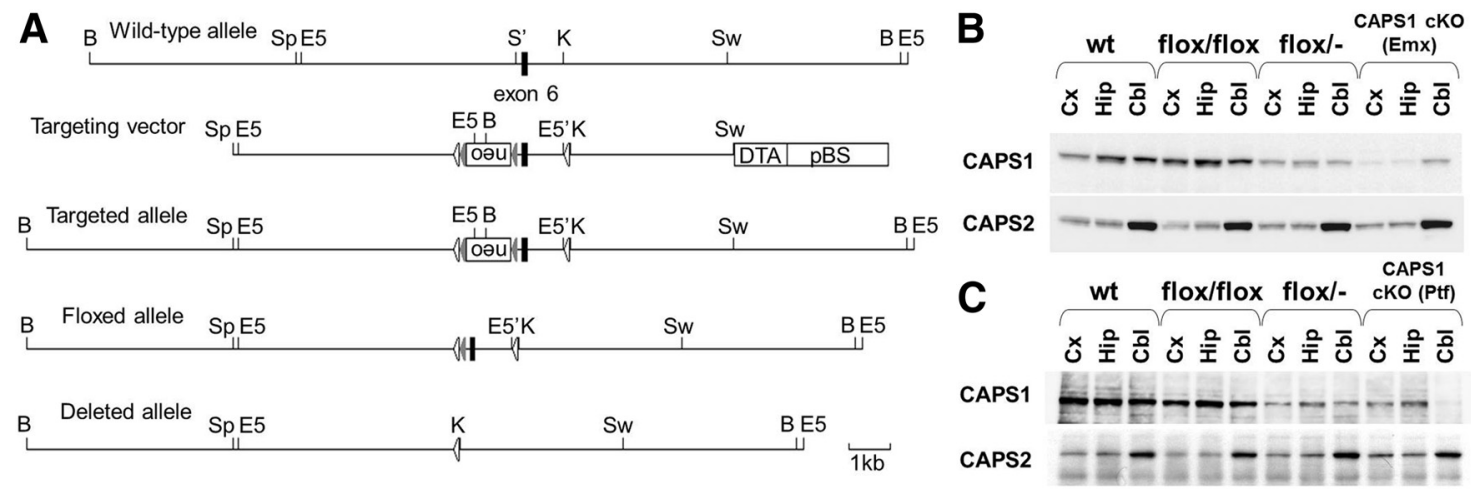

Figure 1. Generation of Caps $1 \mathrm{CKO}$ mice. $A$, The genomic structure of the mouse Caps 1 gene (top line) and illustrations of the targeting vector (second line), the resultant targeted allele (third line), the floxed allele (fourth line), and the deleted allele (bottom line) are shown. The filled box denotes exon 6. Restriction enzyme sites: B, BamHI; E5, EcoRV; K, Kpnl; $S^{\prime}$, Sall (artificially generated); Sp, Spel; Sw, Swal. B, C, Immunoblot analysis of the neocortex (CX), hippocampus (Hip), and cerebellum (Cbl) of the P28 wild-type (wt), flox/flox, flox/-, and Caps1 cK0 (B, forebrain Caps1 CK0; C, cerebellum Caps1 CK0) mice. Protein lysates from these three brain regions were immunoblotted with anti-CAPS1 (top) and anti-CAPS2 antibody (bottom).

brain remain unclear, because Caps1 knock-out mice die shortly after birth (Speidel et al., 2005).

To analyze the function of CAPS1 in the brain, we generated two Caps1 conditional knock-out (cKO) mouse lines using the Cre-loxP recombination system: 1) one with the forebrainspecific Emx1 promoter; and 2) the other with the cerebellumspecific Ptfla promoter. Both cKO lines were born normally and grew to the adult stage. Using these two lines, we were able to examine, for the first time, the effects of CAPS1 deficiency on cellular and synaptic functions in postnatal mouse brain. Our findings suggest that CAPS1 plays a critical role in the TGN-DCV pathway and that it affects synaptic transmission by regulating the density of DCVs.

\section{Materials and Methods}

Animals. All experimental protocols were approved by the Institutional Animal Care and Use Committee of RIKEN Brain Science Institute, Gunma University, and the Tokyo University of Science.

Caps1 knock-out mice. A $10.5 \mathrm{~kb}$ genomic fragment containing exon 6 of the mouse Caps1 gene was obtained from the genomic DNA of C57BL/6 mice and was used to construct the targeting vectors (Fig. 1A). One loxP sequence was inserted at the KpnI site, and the phosphoglycerate kinase-neomycin resistance (neo) cassette, flanked by another loxP sequence and a pair of frt sequences, was inserted into the artificially generated Sall site upstream of exon 6 to generate a loxP-frt-neo-frtexon6-loxP cassette. For negative selection, the diphtheria toxin $\mathrm{A}$-fragment gene cassette was added to the $3^{\prime}$ end of the targeting vector. After transfecting MS12 ES cells (C57BL/6 mouse embryonic stem cell line; Kawase et al., 1994) by electroporation, targeted clones were screened for G418 resistance and analyzed by Southern blot analysis. Chimeric mice were generated by injection of the targeted MS12 ES cells into BALB/c mouse blastocysts and mated with wild-type C57BL/6J mice to obtain heterozygous mutant mice. All of the engineered animals studied were backcrossed with C57BL/6J mice for at least five generations. The Emxl-Cre (Iwasato et al., 2000) and Ptfla-Cre (Yamada et al., 2007) mouse lines were crossed with the floxed mice to delete the exon 6 fragment in a forebrain- and cerebellum-specific manner, respectively.

Antibodies. Rabbit anti-CAPS1 (1:2000 dilution) and anti-CAPS2 (1: 1000 dilution; Sadakata et al., 2004) antibodies and mouse monoclonal anti-actin (1:500 dilution; catalog \#A4700; Sigma-Aldrich) antibody were used for Western blotting. The following primary antibodies were used for immunohistochemistry: rabbit polyclonal anti-brain-derived neurotrophic factor (BDNF; 1:100 dilution; Katoh-Semba et al., 1997), rabbit polyclonal anti-secretogranin II (SgII; 1:2000 dilution; catalog \#K55101R; Biodesign International), mouse monoclonal anti-syntaxin 6 (Stx6; 1:500 dilution; catalog \#610635; BD Biosciences), mouse monoclonal anti-GM130 (1:100 dilution; catalog \#610822; BD Biosciences), rabbit polyclonal anti-calbindin (1:1000 dilution; catalog AB1778; Millipore Bioscience Research Reagents), and mouse monoclonal vesicular glutamate transporter 2 (vGlut2; 1:5000 dilution; catalog \#MAB5504; Millipore Bioscience Research Reagents).

Immunohistochemistry. C57BL/6J male mice were deeply anesthetized with an overdose of diethyl ether and transcardially perfused, initially with PBS and then with Zamboni's fixative ( $2 \%$ paraformaldehyde in 0.1 $\mathrm{M}$ phosphate buffer, $\mathrm{pH} 7.4$, containing $0.2 \%$ picric acid). Tissues were dissected, postfixed in Zamboni's fixative at $4^{\circ} \mathrm{C}$ for $5 \mathrm{~h}$, and cryoprotected by immersion in $15 \%$ sucrose in PBS overnight at $4^{\circ} \mathrm{C}$. After embedding in Tissue-Tek OCT compound (Sakura Finetek), tissues were frozen in dry ice powder, and sectioned at a thickness of $14 \mu \mathrm{m}$ using a cryostat (CM1950; Leica) at $-18^{\circ} \mathrm{C}$. The sections were air dried for $1 \mathrm{~h}$ and rinsed in PBS three times. After blocking with 5\% bovine serum albumin (BSA) and $0.3 \%$ Triton X-100 in PBS at room temperature for $1 \mathrm{~h}$, the sections were incubated at $4^{\circ} \mathrm{C}$ overnight with the primary antibody in an immunoreaction buffer $(2 \times$ PBS containing $0.3 \%$ Triton $\mathrm{X}-100$ and $1 \%$ BSA). The sections were then rinsed in PBS, reacted at room temperature for $1 \mathrm{~h}$ with the secondary antibody in the immunoreaction buffer, and given a final rinse in PBS. Immunoreacted sections were mounted with Vectashield mounting medium (Vector Laboratories) and observed with a microscope (BX51; Olympus) equipped with a CCD camera (VB-7000; Keyence). Digital images were processed using Adobe Photoshop 6.0 software (Adobe Systems). To quantify immunoreactivity, grayscale images were converted to binary (black/white) images, and the region of interest was analyzed using NIH ImageJ software.

Electron microscopy. Under deep anesthesia with sodium pentobarbital (Nembutal; $250 \mathrm{mg} / \mathrm{kg}$, i.p.), P21 mice were transcardially perfused with $2 \mathrm{ml}$ of saline, followed by $25 \mathrm{ml}$ of a mixture of $2.5 \%$ glutaraldehyde and $2 \%$ paraformaldehyde in $0.1 \mathrm{M} \mathrm{PB}$. Brains were dissected and immersed in the same fixative at $4^{\circ} \mathrm{C}$ overnight. The hippocampus and cerebellum were cut into $300 \mu \mathrm{m}$ transverse slices on a microslicer (VT1000S; Leica) and postfixed in cold $1 \% \mathrm{OsO}_{4}$ solution for $1 \mathrm{~h}$. After dehydration in a graded series of alcohol solutions, slices were embedded in epoxy resin (EPON 812; TAAB Laboratories). Serial ultrathin $70 \mathrm{~nm}$ sections were cut on an ultramicrotome (EM UC6; Leica), mounted on 200 mesh uncoated copper grids, and metal stained with uranyl acetate/lead citrate. The grids were examined with a transmission electron microscope (1200EX; Jeol) at $80 \mathrm{kV}$.

Electrophysiology. Parasagittal cerebellar slices (200 $\mu \mathrm{m}$ thick) were prepared from Caps1 cKO mice and wild-type littermates (P21-P42) as described previously (Kakegawa et al., 2008). Whole-cell patch-clamp recordings were made from visually identified Purkinje cells using a $60 \times$ water-immersion objective attached to an upright microscope (BX51WI; Olympus) at room temperature. Because the time course of the maturation of the climbing fiber inputs onto Purkinje cells differs somewhat in the various lobules and subdivisions (i.e., bank, sulcus, and gyrus; Nishiyama and Linden, 2004), we restricted our recordings to the Pur- 

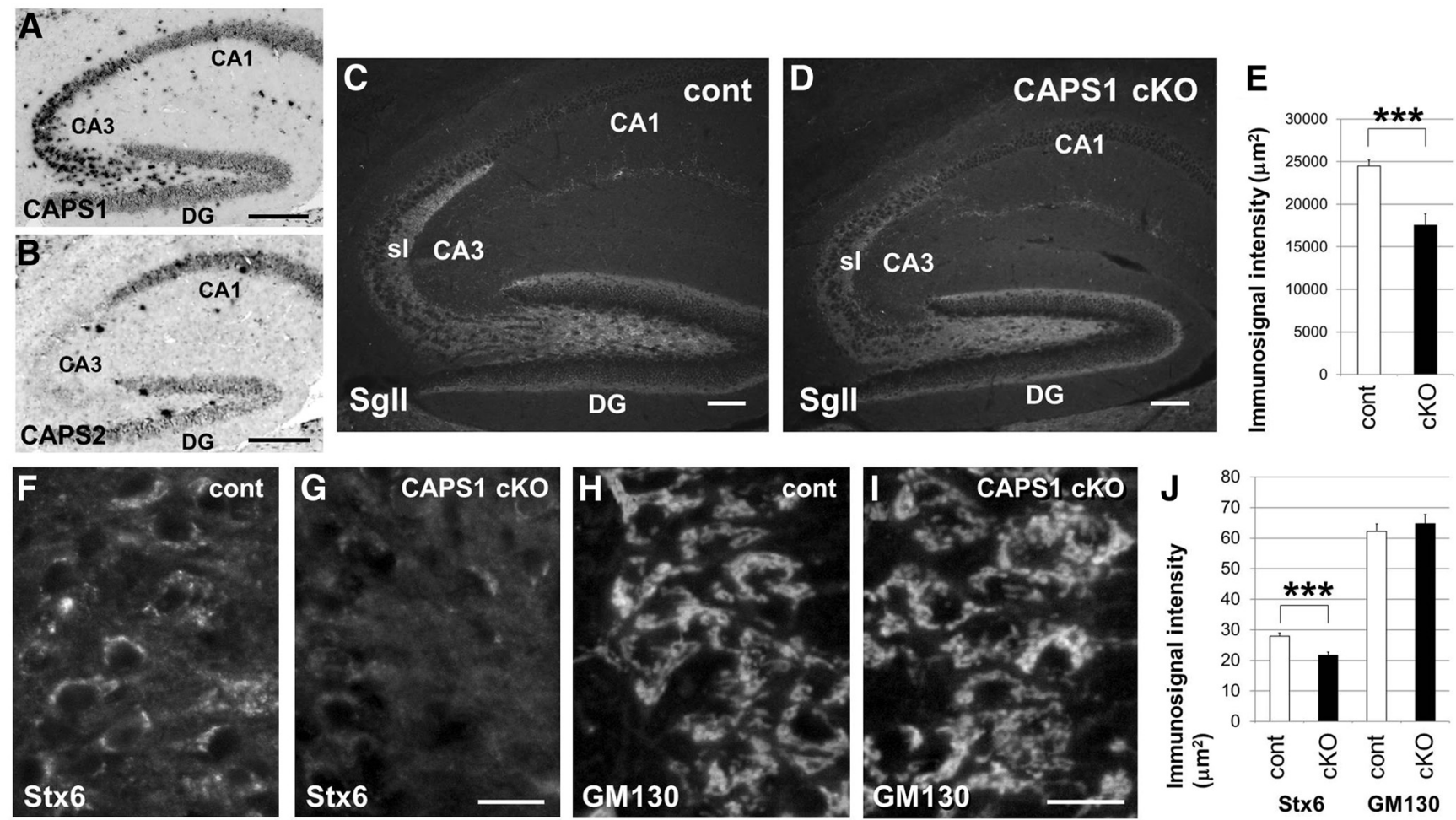

Figure2. Stx6 immunolabeling was diffusely distributed in the soma in Caps 1 CK0 mice. $A, B$, Cellularlocalization of Caps $1(\boldsymbol{A})$ and Caps2 (B) mRNA by in situ hybridization in the hippocampus of P21 wild-type mice. Scale bar, $50 \mu \mathrm{m}$. C, D, Immunohistochemical localization of Sgll in sagittal sections of the hippocampus in control ( flox/-) (cont; $($ ) and Caps 1 cK0 [flox/-, Emx 1(+/-)] (D) mice at P21. sl, Stratum lucidum. Scale bar, $25 \mu \mathrm{m}$. E, Sgll immunolabeling intensities in the stratum lucidum of control (white bar; 8 sections from 4 mice) and Caps 7 cKO (black bar; 6 sections from 3 mice) mice are shown. Error bars indicate the SEM. ${ }^{* *} p=0.000302$, by Student's $t$ test. $\boldsymbol{F}-\boldsymbol{I}$, Sagittal sections of control $(f l o x /-)(\boldsymbol{F}, \boldsymbol{H})$ and Caps1 cK0 $[f l o x /-, E m x 1(+/-)](\boldsymbol{G}, \boldsymbol{I})$ P21 hippocampus, showing CA3 pyramidal cells immunostained for Stx6 (F, G) and GM130 (H,I). Scale bar, $20 \mu \mathrm{m}$.J, Immunolabeling intensities in control (white bar) and Caps 1 CKO (black bar) mice are shown. Stx 6 ( $n=70$ for control and $n=70$ for Caps 1 cK0) and GM130 ( $n=46$ for control and $n=54$ for Caps1 CKO) immunostaining was performed on seven sections from three mice. Error bars indicate the SEM. ${ }^{* * *} p=0.0000289$, by Student'st test.

A

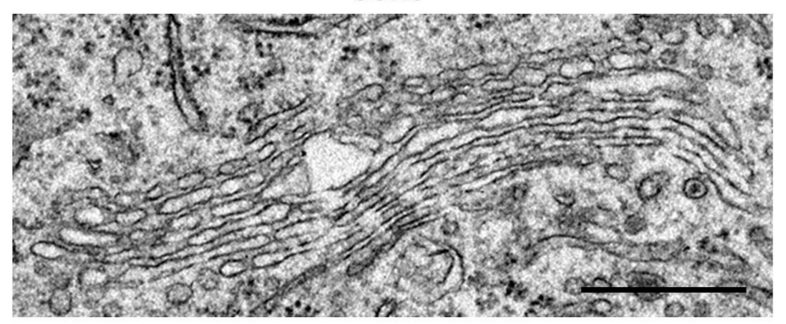

B

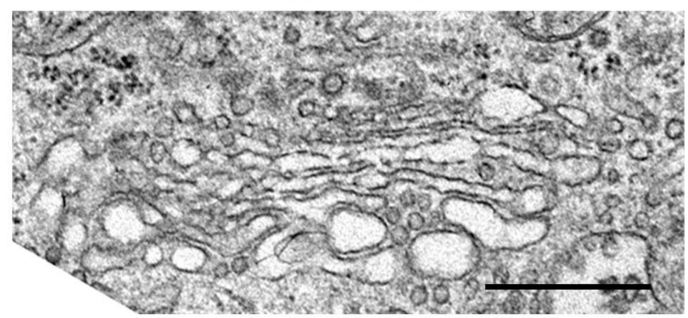

D

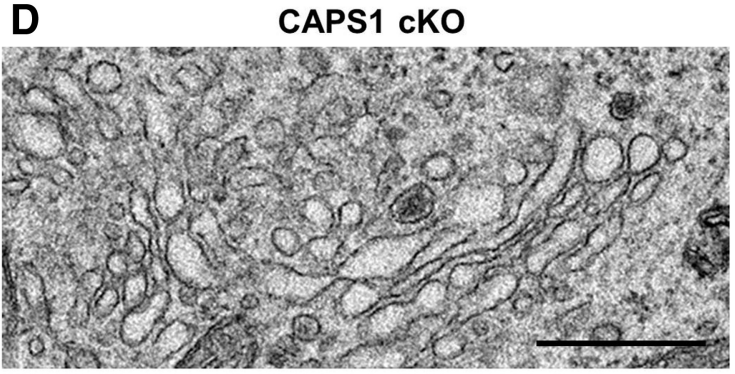

Figure 3. Caps 1 knock-out results in dilated Golgi cisternae in hippocampal neurons. $A, B$, Electron micrographs of Golgi structures in hippocampal CA3 pyramidal cells in control ( flox/- $)(\boldsymbol{A})$ and Caps1 cK0 [flox/-, Emx1(+/-)] (B) mice at P21. C, D, Electron micrographs of Golgi structures in hippocampal dentate granule cells in control ( flox/-) (cont; $\boldsymbol{C}$ and Caps1 cK0 [flox/- , Emx1(+/-)] (D) mice at P21. Scale bars, $500 \mathrm{~nm}$.

kinje cells positioned at the bank regions of lobules IV-VII. The resistance of the patch pipettes was $2-4 \mathrm{M} \Omega$ when filled with an intracellular solution composed of the following (in $\mathrm{mM}$ ): 150 Cs-gluconate, 10 HEPES, $4 \mathrm{MgCl}_{2}, 4 \mathrm{Na}_{2} \mathrm{ATP}, 1 \mathrm{Na}_{2} \mathrm{GTP}, 0.4$ EGTA, and 5 lidocaine n-ethyl bromide, pH 7.25 (295 mOsm/kg). The solution used for slice storage and recording consisted of the following (in $\mathrm{mm}$ ): $125 \mathrm{NaCl}, 2.5$ $\mathrm{KCl}, 2 \mathrm{CaCl}_{2}, 1 \mathrm{MgCl}_{2}, 1.25 \mathrm{NaH}_{2} \mathrm{PO}_{4}, 26 \mathrm{NaHCO}_{3}$, and 10 D-glucose (bubbled continuously with a mixture of $95 \% \mathrm{O}_{2}$ and $5 \% \mathrm{CO}_{2}$ ). Picro- 


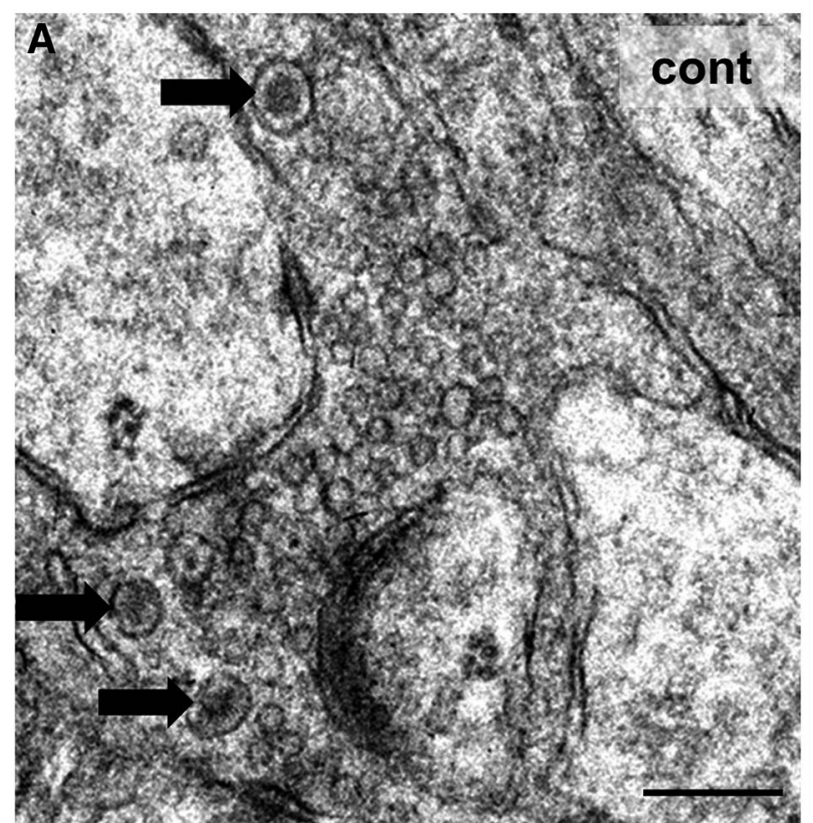

C

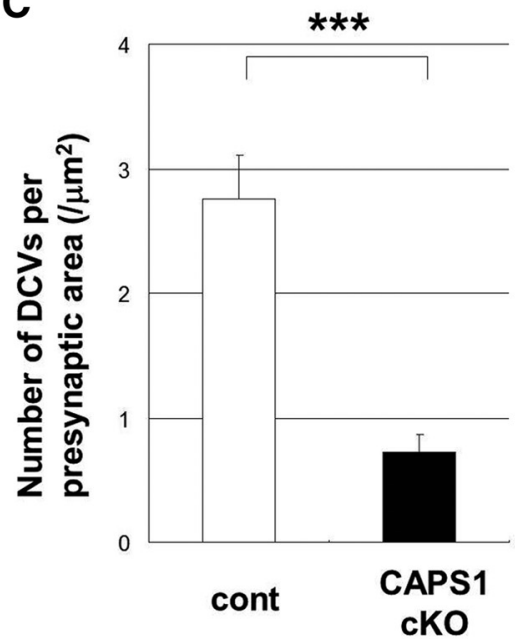

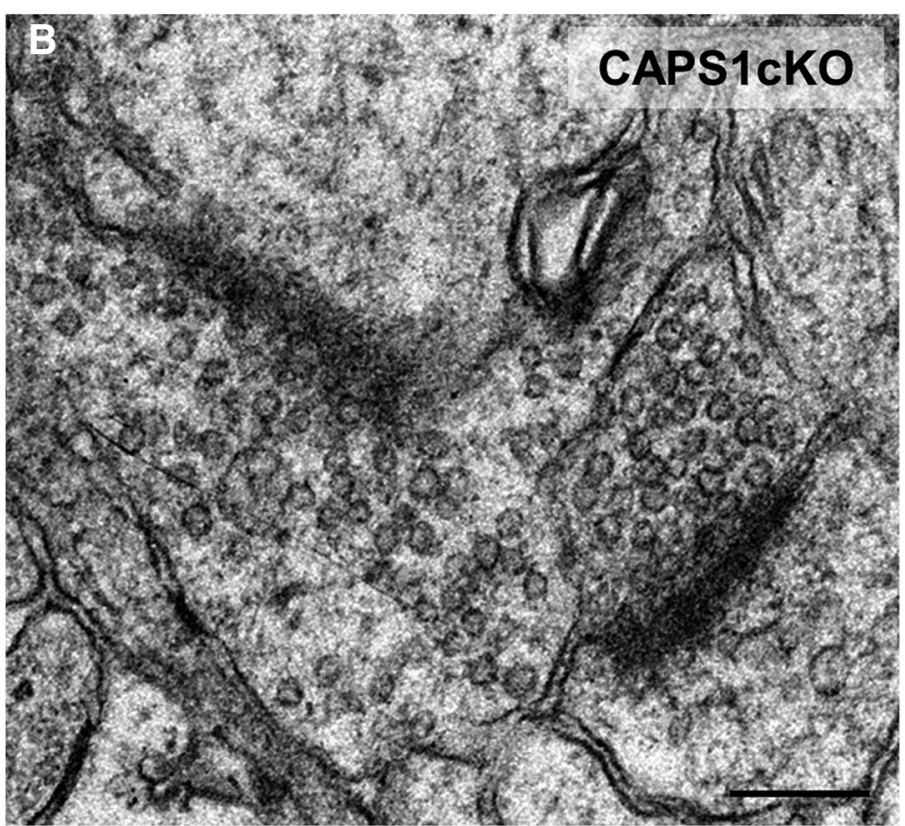

E

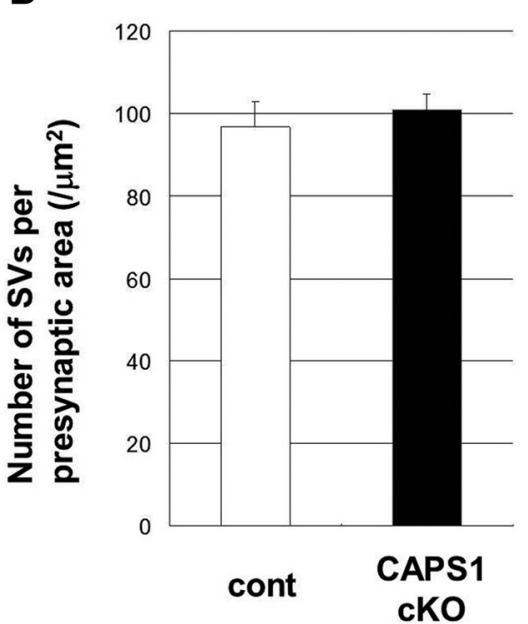

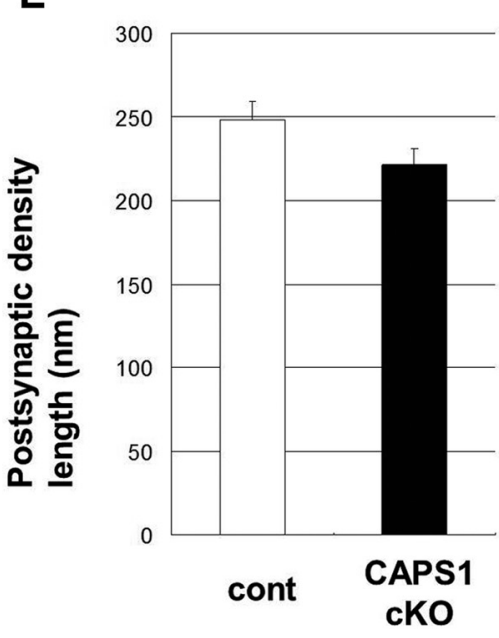

Figure 4. Caps 1 knock-out results in a lower density of DCVs in the hippocampal CA3 region. $A, B$, Electron micrographs of the presynaptic area in the hippocampal CA3 region in a P21 control $($ flox/-) mouse $(\boldsymbol{A})$ and in a Caps1 CKO [flox/-, Emx1(+/-)] mouse (B). Black arrows point to DCVs. Scale bars, $200 \mathrm{~nm}$. C, Number of DCVs per presynaptic area (per square micrometers) in control mice (cont; white bar; $n=22$ ) and in Caps 1 cK0 mice (black bar; $n=32$ ) at P21. ${ }^{* * *} p=0.00022$, by Student's $t$ test. $\boldsymbol{D}$, Number of SVs per presynaptic area (per square micrometers) in control mice (white bar; $n=22$ ) and in Caps 1 cK0 mice (black bar; $n=32$ ) at P21. $E$, The length of the postsynaptic density (in micrometers) in control mice (white bar; $n=39$ ) and in Caps 1 cK0 mice (black bar; $n=62$ ) at P21. The error bars indicate the SEM.

toxin (100 $\mu \mathrm{M}$; Sigma-Aldrich) was always present in the saline to block the inhibitory inputs.

To evoke EPSCs from climbing fiber and parallel fiber inputs onto Purkinje cells, square pulses were applied with a stimulating electrode placed on the granular layer $(10 \mu \mathrm{s}, 0-200 \mu \mathrm{A})$ and the molecular layer $(\sim 50 \mu \mathrm{m}$ away from the pial surface; $10 \mu \mathrm{s}, 0-200 \mu \mathrm{A})$, respectively. Selective stimulation of climbing fibers and parallel fibers was confirmed by paired-pulse depression and paired-pulse facilitation, respectively, of evoked EPSC amplitudes using a $50 \mathrm{~ms}$ interstimulus interval. Current responses were recorded with an Axopatch 200B amplifier (Molecular Devices), and the pClamp system (version 9.2; Molecular Devices) was used for data acquisition and analysis. Signals were filtered at $1 \mathrm{kHz}$ and digitized at $4 \mathrm{kHz}$.

\section{Results}

Generation of forebrain-specific and cerebellum-specific Caps1 cKO mice

A conditional Caps1 allele was generated by gene targeting in embryonic stem cells (Fig. 1A). We used two different brain region-specific cKO systems. One is the forebrain-specific $\mathrm{cKO}$ system using Emx1-Cre $\left(E m \times 1^{C r e /+}\right)$ knock-in mice that show extensive Cre expression in the neocortex, hippocampus, and olfactory bulb but negligible expression in other brain regions (Iwasato et al., 2000). We crossed Emx1 ${ }^{\mathrm{Cre} /+}$ mice with heterozygous Caps1 null mutant $\left(\right.$ Caps1 $\left.{ }^{+/-}\right)$mice to obtain doubleheterozygous $\left(E m x 1^{\mathrm{Cre} /+} \mathrm{Caps} 1^{+/-}\right)$mice. We then crossed the double-heterozygote with homozygous floxed Caps1 (Caps1 $1^{\text {flox/flox }}$ ) mice to obtain $E m x 1^{\text {Cre/+}}-C a p s 1^{\text {flox/- }}$ mice (hereafter referred to as "forebrain Caps1 cKO" mice). The other cKO system used is the cerebellum-specific system using Ptfla-Cre $\left(\mathrm{Ptfla}^{\mathrm{Cr} /+}\right)$ knock-in mice, which show extensive Cre expression in cerebellar GABAergic neurons and inferior olive neurons (Pascual et al., 2007; Yamada et al., 2007). We crossed the double-heterozygote $\left(\mathrm{Ptfla}^{\mathrm{Cre} /+} \mathrm{Caps}^{+/-}\right)$with homozygous floxed Caps1 (Caps $1^{\text {flox/flox }}$ ) mice to obtain Ptfla $a^{\mathrm{Cre} /+}-\mathrm{Caps} 1^{\text {flox/- }}$ mice (hereafter referred to as "cerebellum Caps1 cKO" mice). No overt phenotype has thus 

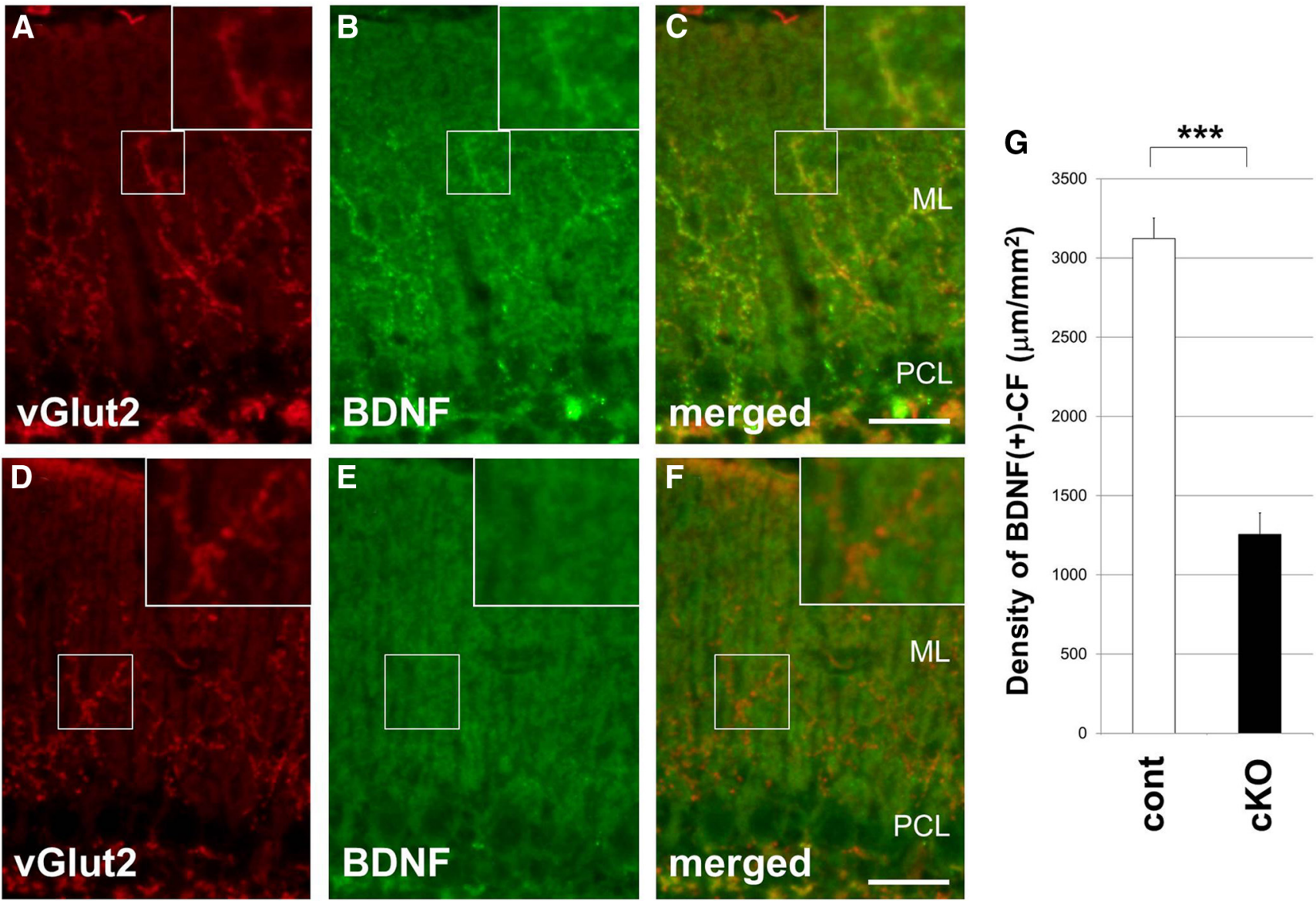

Figure 5. Impaired trafficking of BDNF along climbing fibers in the Caps1 $\mathrm{CKO}$ mouse cerebellum. $\boldsymbol{A}-\boldsymbol{F}$, Sagittal sections of $\mathrm{P} 21$ control $(\mathrm{flox} /-)(\boldsymbol{A}-\boldsymbol{C})$ and $\mathrm{Caps} 1 \mathrm{CKO}[\mathrm{flox} /-$, Emx $1(+/-)]$ $(\boldsymbol{D}-\boldsymbol{F})$ cerebella immunolabeled with an anti-vGlut2 antibody $(\boldsymbol{A}, \boldsymbol{D})$ and an anti-BDNF antibody $(\boldsymbol{B}, \boldsymbol{E})$. Merged images are shown in $\boldsymbol{C}$ and $\boldsymbol{F}$. Insets, Higher magnification. $M$ L, Molecular layer; $\mathrm{PCL}$, Purkinje cell layer. Scale bars, $20 \mu \mathrm{m}$. G, Density of BDNF-positive climbing fibers in the cerebellar molecular layer of control (white bar; 14 sections from 4 mice) and Caps 1 cKO (black bar; 13 sections from 4 mice) mice. Error bars indicate the SEM. ${ }^{* * *} p=1.17 \times 10^{-13}$, by Student's $t$ test.

far been observed in $\mathrm{Em} \times 1^{\mathrm{Cre} /+}$ or $\mathrm{Ptfla} \mathrm{a}^{\mathrm{Cre} /+}$ mice compared with wild-type animals (Krapp et al., 1998; Iwasato et al., 2000; Kawaguchi et al., 2002).

Both of the Caps1 cKO mouse lines were viable and exhibited no overt abnormalities in body shape or gross anatomy. Western blot analysis showed a dramatic reduction in CAPS1 expression in the neocortex and hippocampus of the forebrain cKO mice compared with their control ( flox/-) littermates (Fig. 1B, top). Similarly, CAPS1 expression was markedly reduced in the cerebellum of the cKO mice compared with their control ( flox/-) littermates (Fig. 1C, top). In comparison, the expression levels of CAPS2 (used as a control) in the neocortex, hippocampus, and cerebellum were quite similar among the wild-type, flox/flox, flox/-, and Caps1 cKO mice (Fig. 1B, C, bottom).

\section{Caps1 knock-out causes impairments in the trans-Golgi cisternae and DCVs in hippocampal neurons}

In the mouse hippocampus, Caps1 mRNA was expressed at the highest level in the CA3 region and at intermediate levels in the dentate gyrus (DG) and CA1 region (Fig. 2A), whereas Caps2 mRNA was expressed at the highest level in the CA1 region and at an intermediate level in the DG (Fig. $2 B$ ). Interestingly, in the stratum lucidum of the CA3 region, which receives mossy fiber inputs from granule cells of the DG, the intense immunolabeling for the DCV marker protein SgII found in flox/- mice (Fig. 2C) was comparatively reduced in forebrain Caps1 cKO mice (Fig. $2 D, E)$.

We suggested previously that CAPS1 plays an important role in DCV trafficking in the Golgi complex (Sadakata et al., 2010). To investigate this possibility, we first analyzed immunostaining patterns of Golgi marker proteins in the CA3 pyramidal cell layer (Fig. 2F-I). Immunoreactivity for syntaxin 6 (Stx6, a TGN marker) was observed as an intense cluster around the peripheral region of nuclei, probably representing the Golgi apparatus, in CA3 pyramidal cell soma of control mice (Fig. $2 F$ ). In comparison, only weak immunoreactivity, diffusely distributed in the soma, was observed in the forebrain Caps1 cKO mice (Fig. $2 G)$. However, there was no apparent difference in immunoreactivity for GM130 [a cis-Golgi network (CGN) marker] between the control (Fig. $2 \mathrm{H}$ ) and cKO (Fig. 2I) mice. Statistical analysis revealed a significant difference in Stx6 immunoreactivity, but not in GM130 immunoreactivity, between control and Caps1 cKO animals (Fig. 2J).

We analyzed the ultrastructure of the Golgi apparatus in hippocampal CA3 pyramidal neurons using electron microscopy (Fig. 3). Forebrain Caps1 cKO mice had relatively dilated structures in the identifiable cisternae, which were predominantly on the trans side of the Golgi stack (Fig. 3B), compared with control mice (Fig. 3A). Similar dilated Golgi cisternae were also observed in the DG region of cKO mice (Fig. $3 D$ ) but not in flox/- mice 

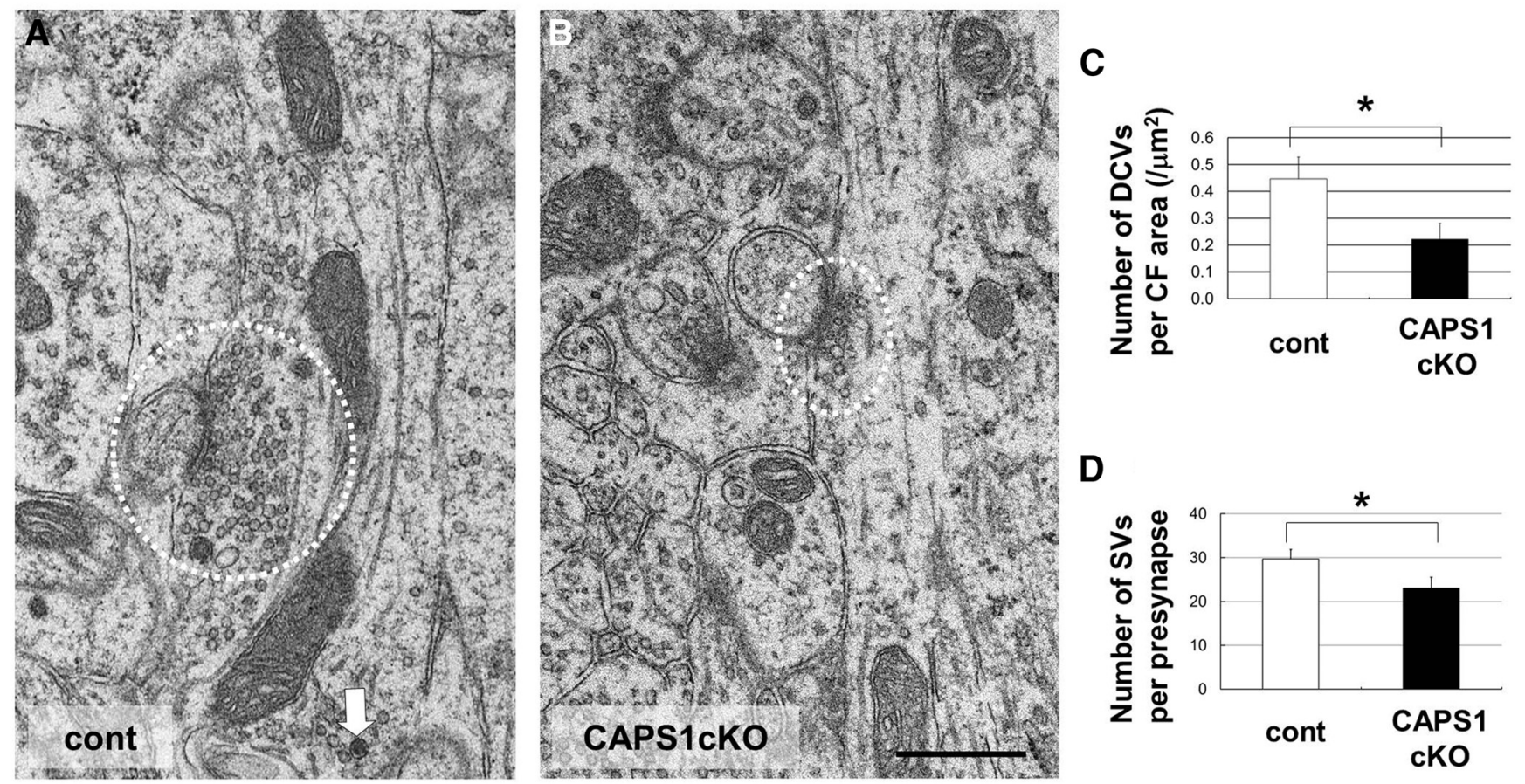

Figure 6. Caps 1 knock-out results in a lower density of SVs and DCVs in climbing fibers. A, B, Electron micrographs of a climbing fiber in P21 control ( flox/-) (cont; $A)$ and Caps 1 cK0 [flox/- , Emx $1(+/-)]$ cerebellum $(\boldsymbol{B})$. The white dotted line indicates synapses. White arrows point to DCVs. Scale bar, $500 \mathrm{~nm}$. C, Number of DCVs per climbing fiber area (per square micrometers) in control mice (white bar; $n=15$ ) and Caps 1 CKO mice (black bar; $n=19$ ) at P21. ${ }^{*} p=0.029$, by Student's $t$ test. $\boldsymbol{D}$, Number of SVs per presynapse in control mice (white bar; $\left.n=29\right)$ and Caps 1 cK0 mice (black bar; $n=32$ ) at P21. ${ }^{*} p=0.048$, by Student's $t$ test. The error bars indicate the SEM.

(Fig. 3C). Together, these findings suggest that CAPS1 deficiency perturbs the structure of the trans-cisternae of the Golgi complex in hippocampal CA3 pyramidal cells and DG granule cells.

We examined the number of presynaptic DCVs and synaptic vesicles (SVs), and the morphology of postsynaptic structures in the CA3 stratum lucidum, the DG-CA3 synaptic region, in flox/- (Fig. 4A) and forebrain Caps1 cKO mice (Fig. 4B). Interestingly, cKO mice had a lower density of DCVs in the presynaptic terminal compared with flox/- mice (Fig. 4C), suggesting a reduction of DCVs in the DG granule cells of cKO mice. However, there was no difference in the density of SVs (Fig. 4D) or the length of the postsynaptic density (Fig. $4 E$ ) between control and cKO mice.

Caps1 knock-out perturbs DCVs and SVs and impairs synaptic transmission in cerebellar climbing fiber-Purkinje cell synapses

In the cerebellar cortex, CAPS1 is localized in the climbing fibers, axons of the inferior olive nuclei (ION), which innervate the proximal dendrites of Purkinje cells. In contrast, CAPS2 predominates in the parallel fibers, axons of granule cells, which innervate the distal dendrites of Purkinje cells (Sadakata et al., 2004, 2006). To clarify the role of CAPS1 in the trafficking of secretary substances along the axon, we focused on climbing fibers. We first analyzed the immunolocalization of a climbing fiber marker, vGlut2, which is known to be expressed in the ION and localized to climbing fiber terminals. vGlut2 appeared normally distributed along the proximal region of Purkinje cell dendrites in the molecular layer of cerebellum Caps1 cKO mice at P21 (Fig. 5D) compared with control ( flox/-) mice (Fig. 5A). In the control mice, the immunostaining pattern for the DCV marker SgII appeared indicative of climbing fibers and was similar to that of vGluT2. However, in Caps1 cKO mice, SgII immunoreactivity was too weak to detect, suggesting a decrease in the number of SgII-positive DCVs or a reduction in the expression level of SgII in the climbing fibers of cKO mice (data not shown).

Brain-derived neurotrophic factor (BDNF) is known to be expressed in the ION and transported, probably via DCVs or DCV-like secretory vesicles, along climbing fibers (Conner et al., 1997). In the control cerebellum, much of the intense fiber-like immunolabeling for BDNF (Fig. 5B) was closely localized with that for vGlut2 (Fig. 5C). (Note that, in the molecular layer, there is a diffuse intermediate level of BDNF immunoreactivity arising from the numerous granule cell-derived parallel fibers). In comparison, this climbing fiber-derived BDNF immunoreactivity was diminished in $\mathrm{CKO}$ mice (Fig. 5E). Statistical analysis revealed a significant difference in the density of BDNFimmunoreactive climbing fibers in the molecular layer of the cerebellum between control and Caps1 cKO mice (Fig. 5G).

Next, we examined the presynaptic distribution of DCVs and SVs in climbing fiber-Purkinje cell synapses using electron microscopy. Cerebellum Caps1 cKO mice had a lower density of DCVs in the presynaptic area than control mice (Fig. 6A-C), again suggesting a reduction of synaptic DCVs in the climbing fibers in these mice. Interestingly, the number of SVs per presynapse was also lower in cKO mice than in controls (Fig. $6 A, B, D$ ), suggesting that CAPS1 deficiency affects the presynaptic distribution of SVs in the climbing fibers as well.

To examine the effects of cerebellar CAPS1 deficiency at the synaptic level, we first investigated the electrophysiological properties of parallel fiber-Purkinje cell and climbing fiber-Purkinje cell synapses. In parallel fiber-Purkinje cell synapses, no significant difference was found between wild-type and Caps1 cKO mice in the peak amplitude of the EPSCs (Fig. $7 A, B$ ), indicating that basic synaptic transmission in $\mathrm{cKO}$ mice is unimpaired. Paired-pulse facilitation at parallel fiber-Purkinje cell synapses, 
A PF-EPSC

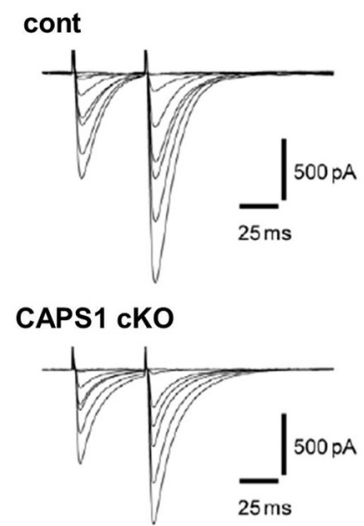

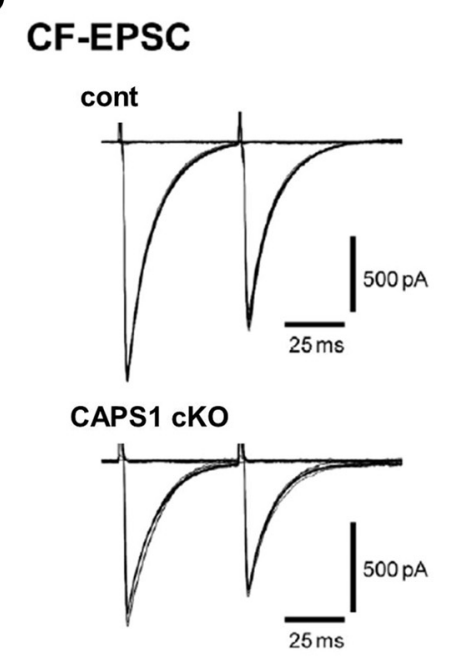

B

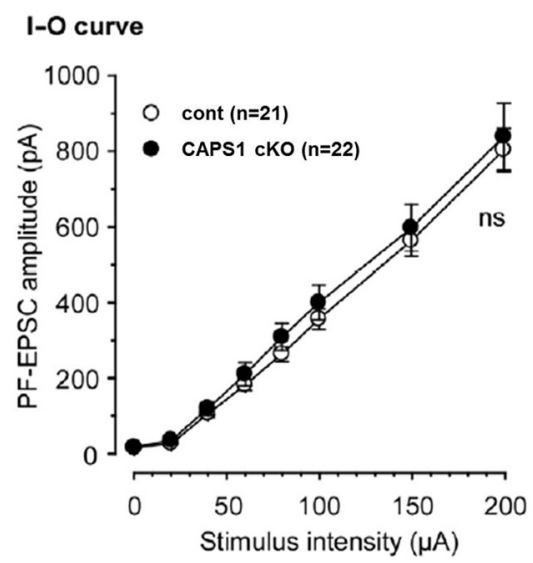

E

C

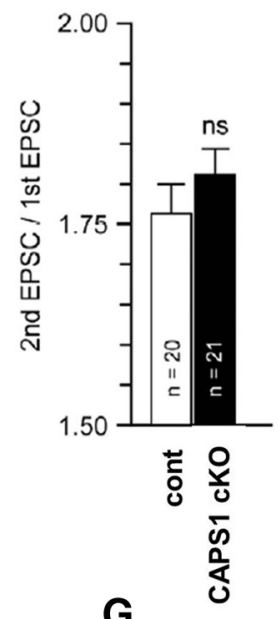

$\mathbf{F}$

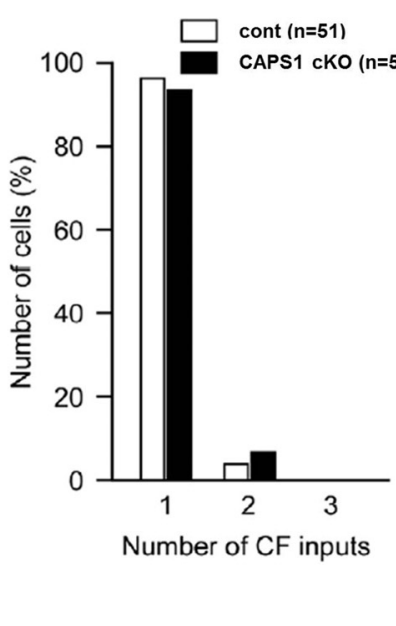

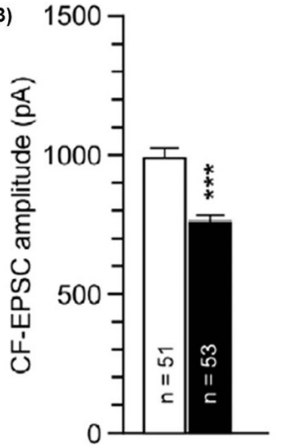

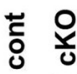

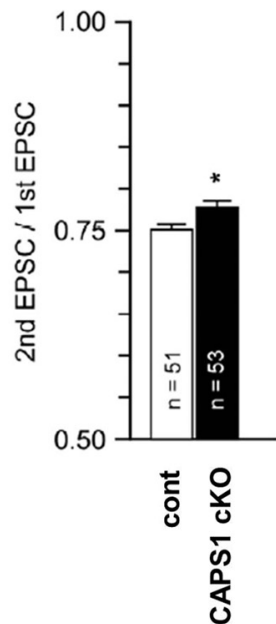

Figure 7. Reduced EPSC amplitude and lower release probability at climbing fiber (CF)-Purkinje cell synapses in Caps 1 CKO mice. $A$, Representative EPSC traces evoked by parallel fiber (PF) stimuli of different stimulus intensities $\left(0-200 \mu \mathrm{A}, 10 \mu \mathrm{s}, 50 \mathrm{~ms}\right.$ interstimulus interval, $\left.V_{\mathrm{h}}=-80 \mathrm{mV}\right)$. B, Plots showing the input- output (I-0) relationship of the parallel fiber-EPSC amplitude in wild-type littermates (open circles; $n=21$ ) and Caps 1 KO mice (filled circles; $n=22$ ). C , The mean paired-pulse ratio of parallel fiber-EPSCs in each genotype ( 50 ms interstimulus interval). $\boldsymbol{D}$, Representative EPSC traces evoked by climbing fiber (CF) stimuli of different stimulus intensities $\left(0-200 \mu \mathrm{A}, 10 \mu \mathrm{s}, 50 \mathrm{~ms}\right.$ interstimulus interval, $\left.V_{\mathrm{h}}=-10 \mathrm{mV}\right)$. $E$, A histogram showing the relationship between the percentage of the number of Purkinje cells and the number of climbing fiber inputs onto a single Purkinje cell in control (open columns; $n=51$ ) and Caps 7 cKO (filled columns; $n=53$ ) mice. $F$, Averaged climbing fiber-EPSC amplitudes in control and Caps 1 CKO mice. ${ }^{* * *} p=3.28 \times 10^{-6}$, by the Mann-Whitney U test. G, The mean paired-pulse ratio of climbing fiber-EPSCs in each genotype (50 ms interstimulus interval). ${ }^{*} p=0.016$, by the Mann-Whitney $U$ test. The error bars indicate the SEM. cont; Control.

which is a form of short-term plasticity reflecting presynaptic function (Zucker and Regehr, 2002), was also unchanged in cKO mice compared with control mice (Fig. 7C). Morphological assessment of climbing fiber-Purkinje cell synapses in the adult cerebellum revealed that Purkinje cells in $\mathrm{cKO}$ mice were normally innervated by a single climbing fiber, similar to control mice (Fig. 7E). However, climbing fiber-EPSCs recorded from cKO mice showed a reduced climbing fiber-EPSC amplitude and enhanced paired-pulse depression, reflecting lower presynaptic release probability (Zucker and Regehr, 2002; Fig. 7 F, G). Together, these results suggest that CAPS1 deficiency perturbs synaptic transmission at climbing fiber-Purkinje cell synapses by affecting presynaptic functioning.

\section{Discussion}

To overcome the neonatal lethality in Caps1 null (KO) mice (Speidel et al., 2005) and to better understand the in vivo effects of Caps1 deficiency on the mouse nervous system, we generated forebrain-specific and cerebellum-specific Caps1 cKO mouse lines. In contrast to Caps1 KO mice, both $\mathrm{cKO}$ lines were born normally and grew to the adult stage, allowing us for the first time to analyze loss-of-CAPS1 phenotypes in the postnatal mouse brain.

Western blot analysis revealed a dramatic reduction in CAPS1 expression in the neocortex and hippocampus of the forebrain cKO mice compared with their control (flox/-) littermates. However, there were detectable levels of CAPS1 immunoreactivity in protein samples of the cortex and hippocampus from forebrain cKO mice. Emx1-Cre $\left(E m \times 1^{\mathrm{Cre} /+}\right)$ knock-in mice have extensive Cre expression in the neocortex, hippocampus, and olfactory bulb but negligible expression in other brain regions (Iwasato et al., 2000). However, there are projections to the neocortex and hippocampus from other brain regions, including the raphe, locus ceruleus, and thalamus, in which various types of neurons express CAPS1 (data not shown). Low CAPS1 immuno- 
reactivity was observed around the soma of CA3 and CA1 pyramidal neurons in the Caps1 cKO hippocampus (data not shown). Therefore, the low levels of CAPS1 detected in the neocortex and hippocampus of the forebrain Caps1 cKO mice likely represent protein derived from axonal projections of neurons localized outside the forebrain.

Our previous in vitro CAPS1 KD study, using the rat adrenal pheochromocytoma cell line PC12, showed that CAPS1 plays an important role in the trafficking of DCVs in the Golgi complex by binding ARF4 and ARF5 small GTPases (Sadakata et al., 2010). CAPS1 KD decreases immunoreactivity for chromogranin A (a luminal protein in DCVs) in neurites but results in accumulation of the protein in the Golgi complex. Consequently, DCV secretion of chromogranin A into the culture media is reduced. In contrast, transmembrane proteins, including neurotrophin receptors TrkA and TrkB, which are not transported by DCVs, are normally targeted to the cell surface of CAPS1 KD cells. These results indicate that the DCV trafficking pathway, but not the general sorting of TrkA/B, is affected by CAPS1 KD. In the present study, we found that forebrain Caps1 cKO mice have an abnormal pattern of immunoreactivity for the TGN marker Stx6 but not the CGN marker GM130 (Fig. 2). Moreover, we observed dilation of the Golgi cisternae predominantly on the trans side (Fig. 3) and a drastic reduction in the number of DCVs, but not SVs (Fig. 4), in the hippocampus of forebrain Caps1 cKO mice. Together, our findings strongly suggest that CAPS1 proteins play a critical role in DCV trafficking in the TGN in vivo. However, whether other types of vesicular transport at the TGN are affected in neurons in CAPS1 cKO mice remains to be elucidated.

In the cerebellar cortex, CAPS1 is localized in climbing fibers, whereas CAPS2 predominates in parallel fibers (Sadakata et al., 2006). Cerebellum cKO mice showed decreased levels of BDNF along the climbing fibers (axons of BDNF-producing ION neurons) in the molecular layer. However, the climbing fibers appeared normally distributed in the proximal region of Purkinje cell dendrites as revealed by the pattern of climbing fiber-specific vGlut2 immunoreactivity, and they also functionally monoinnervated Purkinje cell dendrites (a hallmark of mature climbing fiber-Purkinje cell connectivity), as revealed by recordings of single climbing fiber-evoked EPSCs. Despite this normal gross morphological appearance, cerebellar CAPS1 deficiency reduced the number of presynaptic DCVs as well as SVs at the climbing fiber-Purkinje cell synapses. This contrasts with the hippocampal CA3 region, in which only presynaptic DCVs were reduced in number (SVs did not appear affected). These findings suggest that diminished BDNF levels may contribute to a reduction in the number of DCVs in the climbing fibers, resulting in a lower SV density within the climbing fiber terminals.

It is intriguing that deficiency of different CAPS family proteins (CAPS1 vs CAPS2) results in distinct presynaptic effects (paired-pulse depression vs paired-pulse facilitation) at different cerebellar synapses (climbing fiber-Purkinje cell vs parallel fiberPurkinje cell). A previous study demonstrated a reduction in the amplitude of evoked EPSCs and mEPSCs in primary-cultured hippocampal neurons from Caps1 KO mice, which was suggested by the authors to be attributable to a decrease in the size of the readily releasable pool (Jockusch et al., 2007). Our present study shows that deficiency of cerebellar CAPS1 reduces climbing fiberEPSC amplitude and enhances paired-pulse depression at climbing fiber-Purkinje cell synapses, suggesting a lowered presynaptic release probability at these contacts. In comparison, our previous study showed that deficiency of cerebellar CAPS2 reduces paired-pulse facilitation at parallel fiber-Purkinje cell synapses
(Sadakata et al., 2007a). It remains to be elucidated what unique properties of CAPS1 and CAPS2 allow them to have distinct presynaptic effects at the different synapses.

In conclusion, we examined the effects of CAPS1 deficiency on cellular function (including DCV, SV, TGN, and synaptic properties) in postnatal mouse brain by generating and analyzing Caps1 cKO mice. The forebrain Caps1 cKO mice showed perturbations in presynaptic DCV (but not SV) distribution and in TGN (but not CGN) architecture in the hippocampal DG-CA3 region. In comparison, the cerebellum Caps1 cKO mice showed alterations in presynaptic DCV and SV distribution, climbing fiber BDNF expression, and EPSC and paired-pulse depression (but not paired-pulse facilitation) properties at climbing fiberPurkinje cell synapses. Collectively, these results suggest that CAPS1 plays a critical regulatory role in the DCV pathway, which directly affects presynaptic function and synaptic transmission.

\section{References}

Ann K, Kowalchyk JA, Loyet KM, Martin TF (1997) Novel Ca ${ }^{2+}$-binding protein (CAPS) related to UNC-31 required for $\mathrm{Ca}^{2+}$-activated exocytosis. J Biol Chem 272:19637-19640. CrossRef Medline

Berwin B, Floor E, Martin TF (1998) CAPS (mammalian UNC-31) protein localizes to membranes involved in dense-core vesicle exocytosis. Neuron 21:137-145. CrossRef Medline

Conner JM, Lauterborn JC, Yan Q, Gall CM, Varon S (1997) Distribution of brain-derived neurotrophic factor (BDNF) protein and mRNA in the normal adult rat CNS: evidence for anterograde axonal transport. J Neurosci 17:2295-2313. Medline

Fujita Y, Xu A, Xie L, Arunachalam L, Chou TC, Jiang T, Chiew SK, Kourtesis J, Wang L, Gaisano HY, Sugita S (2007) $\mathrm{Ca}^{2+}$-dependent activator protein for secretion 1 is critical for constitutive and regulated exocytosis but not for loading of transmitters into dense core vesicles. J Biol Chem 282: 21392-21403. CrossRef Medline

Grishanin RN, Kowalchyk JA, Klenchin VA, Ann K, Earles CA, Chapman ER, Gerona RR, Martin TF (2004) CAPS acts at a prefusion step in densecore vesicle exocytosis as a $\mathrm{PIP}_{2}$ binding protein. Neuron 43:551-562. CrossRef Medline

Iwasato T, Datwani A, Wolf AM, Nishiyama H, Taguchi Y, Tonegawa S, Knöpfel T, Erzurumlu RS, Itohara S (2000) Cortex-restricted disruption of NMDAR1 impairs neuronal patterns in the barrel cortex. Nature 406: 726-731. CrossRef Medline

Jockusch WJ, Speidel D, Sigler A, Sørensen JB, Varoqueaux F, Rhee JS, Brose N (2007) CAPS-1 and CAPS-2 are essential synaptic vesicle priming proteins. Cell 131:796-808. CrossRef Medline

Kakegawa W, Miyazaki T, Emi K, Matsuda K, Kohda K, Motohashi J, Mishina M, Kawahara S, Watanabe M, Yuzaki M (2008) Differential regulation of synaptic plasticity and cerebellar motor learning by the C-terminal PDZ-binding motif of GluR $\delta 2$. J Neurosci 28:1460-1468. CrossRef Medline

Katoh-Semba R, Takeuchi IK, Semba R, Kato K (1997) Distribution of brain-derived neurotrophic factor in rats and its changes with development in the brain. J Neurochem 69:34-42. CrossRef Medline

Kawaguchi Y, Cooper B, Gannon M, Ray M, MacDonald RJ, Wright CV (2002) The role of the transcriptional regulator Ptfla in converting intestinal to pancreatic progenitors. Nat Genet 32:128-134. CrossRef Medline

Kawase E, Suemori H, Takahashi N, Okazaki K, Hashimoto K, Nakatsuji N (1994) Strain difference in establishment of mouse embryonic stem (ES) cell lines. Int J Dev Biol 38:385-390. Medline

Krapp A, Knöfler M, Ledermann B, Bürki K, Berney C, Zoerkler N, Hagenbüchle O, Wellauer PK (1998) The bHLH protein PTF1-p48 is essential for the formation of the exocrine and the correct spatial organization of the endocrine pancreas. Genes Dev 12:3752-3763. CrossRef Medline

Liu Y, Schirra C, Stevens DR, Matti U, Speidel D, Hof D, Bruns D, Brose N, Rettig J (2008) CAPS facilitates filling of the rapidly releasable pool of large dense-core vesicles. J Neurosci 28:5594-5601. CrossRef Medline

Nishiyama H, Linden DJ (2004) Differential maturation of climbing fiber innervation in cerebellar vermis. J Neurosci 24:3926-3932. CrossRef Medline

Pascual M, Abasolo I, Mingorance-Le Meur A, Martínez A, Del Rio JA, 
Wright CV, Real FX, Soriano E (2007) Cerebellar GABAergic progenitors adopt an external granule cell-like phenotype in the absence of Ptfla transcription factor expression. Proc Natl Acad Sci U S A 104:5193-5198. CrossRef Medline

Renden R, Berwin B, Davis W, Ann K, Chin CT, Kreber R, Ganetzky B, Martin TF, Broadie K (2001) Drosophila CAPS is an essential gene that regulates dense-core vesicle release and synaptic vesicle fusion. Neuron 31:421437. CrossRef Medline

Sadakata T, Mizoguchi A, Sato Y, Katoh-Semba R, Fukuda M, Mikoshiba K, Furuichi T (2004) The secretory granule-associated protein CAPS2 regulates neurotrophin release and cell survival. J Neurosci 24:43-52. CrossRef Medline

Sadakata T, Itakura M, Kozaki S, Sekine Y, Takahashi M, Furuichi T (2006) Differential distributions of the $\mathrm{Ca}^{2+}$-dependent activator protein for secretion family proteins (CAPS2 and CAPS1) in the mouse brain. J Comp Neurol 495:735-753. CrossRef Medline

Sadakata T, Kakegawa W, Mizoguchi A, Washida M, Katoh-Semba R, Shutoh F, Okamoto T, Nakashima H, Kimura K, Tanaka M, Sekine Y, Itohara S, Yuzaki M, Nagao S, Furuichi T (2007a) Impaired cerebellar development and function in mice lacking CAPS2, a protein involved in neurotrophin release. J Neurosci 27:2472-2482. CrossRef Medline

Sadakata T, Washida M, Iwayama Y, Shoji S, Sato Y, Ohkura T, Katoh-Semba R, Nakajima M, Sekine Y, Tanaka M, Nakamura K, Iwata Y, Tsuchiya KJ, Mori N, Detera-Wadleigh SD, Ichikawa H, Itohara S, Yoshikawa T, Furuichi T (2007b) Autistic-like phenotypes in Cadps2-knockout mice and aberrant CADPS2 splicing in autistic patients. J Clin Invest 117:931943. CrossRef Medline

Sadakata T, Shinoda Y, Sekine Y, Saruta C, Itakura M, Takahashi M, Furuichi $\mathrm{T}$ (2010) Interaction of calcium-dependent activator protein for secretion 1 (CAPS1) with the class II ADP-ribosylation factor small GTPases is required for dense-core vesicle trafficking in the trans-Golgi network. J Biol Chem 285:38710-38719. CrossRef Medline

Sadakata T, Sekine Y, Oka M, Itakura M, Takahashi M, Furuichi T (2012) Calcium-dependent activator protein for secretion 2 interacts with the class II ARF small GTPases and regulates dense-core vesicle trafficking. FEBS J 279:384-394. CrossRef Medline

Speidel D, Varoqueaux F, Enk C, Nojiri M, Grishanin RN, Martin TF, Hofmann K, Brose N, Reim K (2003) A family of $\mathrm{Ca}^{2+}$-dependent activator proteins for secretion: comparative analysis of structure, expression, localization, and function. J Biol Chem 278:52802-52809. CrossRef Medline

Speidel D, Bruederle CE, Enk C, Voets T, Varoqueaux F, Reim K, Becherer U, Fornai F, Ruggieri S, Holighaus Y, Weihe E, Bruns D, Brose N, Rettig J (2005) CAPS1 regulates catecholamine loading of large dense-core vesicles. Neuron 46:75-88. CrossRef Medline

Speidel D, Salehi A, Obermueller S, Lundquist I, Brose N, Renström E, Rorsman P (2008) CAPS1 and CAPS2 regulate stability and recruitment of insulin granules in mouse pancreatic beta cells. Cell Metab 7:57-67. CrossRef Medline

Tandon A, Bannykh S, Kowalchyk JA, Banerjee A, Martin TF, Balch WE (1998) Differential regulation of exocytosis by calcium and CAPS in semi-intact synaptosomes. Neuron 21:147-154. CrossRef Medline

Walent JH, Porter BW, Martin TF (1992) A novel $145 \mathrm{kd}$ brain cytosolic protein reconstitutes $\mathrm{Ca}^{2+}$-regulated secretion in permeable neuroendocrine cells. Cell 70:765-775. CrossRef Medline

Yamada M, Terao M, Terashima T, Fujiyama T, Kawaguchi Y, Nabeshima Y, Hoshino M (2007) Origin of climbing fiber neurons and their developmental dependence on Ptfla. J Neurosci 27:10924-10934. CrossRef Medline

Zucker RS, Regehr WG (2002) Short-term synaptic plasticity. Annu Rev Physiol 64:355-405. CrossRef Medline 